This item was submitted to Loughborough's Research Repository by the author.

Items in Figshare are protected by copyright, with all rights reserved, unless otherwise indicated.

\title{
Modes of climate variability and associated bird communities in India
}

PLEASE CITE THE PUBLISHED VERSION

https://doi.org/10.1111/area.12412

\section{PUBLISHER}

Wiley $@$ Royal Geographical Society (with the Institute of British Geographers).

\section{VERSION}

AM (Accepted Manuscript)

\section{PUBLISHER STATEMENT}

This is the peer reviewed version of the following article: MEHTA, A. and WILBY, R.L., 2018. Modes of climate variability and associated bird communities in India. Area, 50(3), pp. 397-409, which has been published in final form at https://doi.org/10.1111/area.12412. This article may be used for non-commercial purposes in accordance with Wiley Terms and Conditions for Use of Self-Archived Versions.

\section{LICENCE}

CC BY-NC-ND 4.0

\section{REPOSITORY RECORD}

Mehta, A., and Robert Wilby. 2018. "Modes of Climate Variability and Associated Bird Communities in India". figshare. https://hdl.handle.net/2134/28379. 


\title{
Modes of climate variability and associated bird
}

\section{communities in India}

\begin{abstract}
Birds are sensitive to climate variability and change. This pilot study explores variations in bird communities in India under contrasting phases of the El NiñoSouthern Oscillation (ENSO) and Indian Ocean Dipole (IOD). Statistical analyses were performed using monthly bird data for the years 1990-2015 in Goa and Tamil Nadu. Monthly precipitation, temperature, the Oceanic Niño Index and the Dipole Mode Index were used as explanatory variables for species richness (SR) and counts of three marker species (Brahminy Kite, Indian Pond Heron and Lesser Whistling Duck). Due to highly autocorrelated series, small sample sizes and many test permutations there is greater likelihood of Type I errors when interpreting correlation results. However, pooling bird data by climate mode and state revealed that SR was generally greater under EI Niño or negative IOD (locally wet conditions) than under La Niña or positive IOD (locally dry conditions). In Goa, the Brahminy Kite, Indian Pond Heron and Lesser Whistling Duck had significantly higher counts during El Niño than La Niña events. In Tamil Nadu, there were significantly more Kites under negative than positive IOD phases. Regional variations in sensitivity may reflect species-dependent factors such as food availability and security of nesting sites. Further research is needed to establish causal mechanisms between climate mode and SR as well as into the combined effects of ENSO and IOD on bird communities across South Asia.
\end{abstract}

Keywords India, species richness, statistical analysis, climate variability, ENSO, IOD 


\section{Introduction}

Birds are sensitive to climate variability and change (Foden et al. 2013). Inter-annual variability caused by climate modes - such as the El Niño-Southern Oscillation (ENSO) and the Indian Ocean Dipole (IOD) - can therefore, have potentially significant impacts on birds (Favero and Becker 2006). The ENSO is a coupled ocean-atmosphere phenomenon involving fluctuating warm-water (El Niño) and coldwater (La Niña) phases in the equatorial Pacific. El Niño events occur on average every 2-7 years and can be associated with regionally catastrophic floods, droughts, landslides and wildfires (Caviedes 2001; Dai and Wigley 2000).

The IOD is an ocean-atmosphere mode of periodicity 1.5 to 10 years with wind and precipitation anomalies unique to the Indian Ocean (Saji et al. 1999). A positive (negative) IOD phase is characterised by anomalously warm (cold) sea surface temperatures (SSTs) in the western basin and colder (warmer) than normal SSTs off Sumatra. Like ENSO, the IOD also causes rainfall anomalies in areas surrounding the Indian Ocean (Saji et al. 1999).

India's seasons are conventionally categorised as winter (January-February); premonsoon/dry (March-May); summer monsoon (June-September); and winter monsoon (October-December) (IMD 2016). The summer (or South West) monsoon, (SWM) is caused by moist winds from the Arabian Sea which flow over most of India, bringing $70 \%$ of the mean annual rainfall total (Ashok et al. 2004). An abrupt shift in wind patterns to the northeast is caused by the withdrawal of the SWM from the north and central India, signalling onset of the North East Monsoon (NEM) season. Tamil Nadu (TN) receives 60\% of the annual rainfall during this period (IMD 2016). 
Indian Monsoon Rainfall (IMR) is affected by both the ENSO and IOD (Ashok et al. 2001). Warmer SSTs in the eastern Pacific are typically associated with monsoon drought in Maharashtra, Kerala, Karnataka, and Goa. Conversely, cooler Pacific SSTs are generally linked to monsoon floods in the same regions (Krishnamurthy and Goswami 2000). However, during El Niño events, south-east India experiences above normal precipitation in the NEM season (Dai and Wigley 2000). During positive IOD phases India receives above average rainfall whereas negative phases bring rainfall deficits (Ashok et al. 2004). The IOD influences the IMR-ENSO relationship by damping or amplifying ENSO induced anomalous circulation over the region (Ashok et al. 2001). When a strong positive (negative) IOD event coincides with an El Niño (La Niña), the impact of ENSO on IMR is weaker (Ashok et al. 2004).

Previous research into the regional impacts of ENSO/ IOD has evaluated bird reproduction, migration, population dynamics, survival, and other such aspects (Favero and Becker 2006). For example, Feldstein (2003) found that fecundity and survival rates of the Black-Throated Blue Warbler in North America were higher during La Niña years due to improved food availability. In Germany, breeding Common Terns have higher return rates from Africa during La Niña periods (Favero and Becker 2006). Conversely, the Rufous-Crowned Sparrow has greater food availability and less predation by snakes in El Niño years (Feldstein 2003). Darwin's Finches are more numerous during El Niño due to higher reproduction linked to improved plant growth and greater food availability. Subsequently, increased competition for food, territorial fights, killing of eggs and chicks, and higher 
temperatures tend to negatively impact breeding success of the finches (Holmgrem et al. 2001).

Jaksic and Farina (2010) found that El Niño events reduce food for seabirds in the southeast Pacific leading to greater adult mortality and reproductive failure, but water-birds benefit from enlarged habitats. However, Catry et al (2013) assert that food shortages due to low SSTs have detrimental impacts on the entire seabird community. Monticelli et al (2008) report that years with higher SSTs in the western Indian Ocean have lower re-sighting of Roseate Terns on the Aride Islands because some adults refrain from breeding during less favourable conditions. Fewer Steppe Eagles and rapid advances in the phenology of their spring migration through Israel have been related to the IOD, an indicator of weather conditions in the wintering grounds (Zduniak et al. 2010). Hence, there are varied regional and speciesdependent impacts of ENSO and IOD on bird communities.

As far as the authors are aware, this paper is the first to explore the impact of ENSO and IOD on birds in India. Using concurrent and lagged correlation as well as composite analyses, we investigate the impact of precipitation, temperature, ENSO and IOD on bird communities in Goa and Tamil Nadu. We then compare and contrast these impacts spatially and temporally. Section 2 describes the study areas, data and methods of analysis. Section 3 presents the results, Section 4 discusses the key findings, and finally Section 5 draws out the conclusions with suggestions for further research. 


\section{Methods}

Study areas

There are two study areas. Goa is located in the Konkan coastal belt on the west of India (Figure 1). The state has an area of $3,702 \mathrm{~km}^{2}$ and receives most rainfall from the SWM. Goa has a number of endemic species, habitats and ecosystems such as the Bondla Wildlife Sanctuary, St Cruz Marshes, Morjim beach, the Baga saltpans, and Carambolim Lake. Tamil Nadu (TN) has an area of $130,058 \mathrm{~km}^{2}$ and is the southernmost state on the east coast of India (Figure 1) with an ecology that is strongly influenced by the NEM.

\section{Data sources}

All data were drawn from secondary sources for the period January 1990 to March 2015. Monthly mean precipitation was obtained from the Indian Meteorological Department (IMD) in Pune and the Government of India's Indian Institute of Tropical Meteorology (IITM 2015). Precipitation for TN was taken from 20 meteorological stations while for Goa based on two stations. Monthly mean temperature anomalies were obtained from the Climatic Research Unit (CRUTEM4) portal (https://crudata.uea.ac.uk/cru/data/crutem/ge/) using three grid boxes for TN and one for Goa (Osborn \& Jones 2014).

The ENSO and IOD indices originate from the National Oceanic and Atmospheric Administration (NOAA 2015; 2016). The Oceanic Niño Index (ONI) and the Dipole Mode Index (DMI) were used as indicators of ENSO and IOD, respectively. The ONI was chosen over other ENSO indices following Dahlmann (2009). 
Bird data were obtained from eBird (2015), an online archive of bird abundance and distribution, verified by regional experts. Bird data were analysed as species richness $(\mathrm{SR})$ - the number of species sighted in a given period (see Supplementary Information for species lists). In general, SR is preferred to absolute numbers to avoid inconsistent reporting and possible double counting. However, when bird surveys are undertaken by the same organisation using a consistent methodology, the relative abundance of individual species should be robust. Moreover, our chosen marker species - the Brahminy Kite (Haliastur indus), the Indian Pond Heron (Ardeola grayii), and the Lesser Whistling Duck (Dendrocygna javanica) - are all large birds, easily identified, and often in open ground. These species are commonly sighted in both states and found near water sources, which should make them potentially sensitive to climate variability.

\section{Statistical analyses}

Our null hypothesis is that there is no statistically significant association between state-level bird communities (SR or marker species counts) and climate variables (precipitation, temperature, ENSO or IOD). Bird data were analysed via: (1) concurrent and lagged correlations between SR (or counts of marker species) and climate variables at monthly and seasonal timescales (e.g. pre-monsoon and SWM); (2) tests of differences in weather and bird communities when pooling (termed hereafter as "compositing") data by contrasting ENSO and IOD phases, both in isolation and conjunction.

The non-parametric Spearman's rank correlation (rho) was used to explore associations between birds and climate. Sample sizes were adjusted for 
autocorrelation and the $t$-test was used to assess significance of $r$ ho for large datasets $(N>30)$. Following Pearce-Higgins et al. (2015) we applied the Bonferroni correction to the significance level to account for the number of correlation tests performed for each family of inferences. Our Bonferroni thresholds ( $p \leq 0.0012$ for SR and $p \leq 0.0038$ for marker species) heighten the chance of Type II errors (i.e. incorrectly retaining a false null hypothesis). Since this is a preliminary exploration we are wary of missing actual correlations because the test has insufficient power. Hence, we do report weaker relationships for completeness.

The mean, median, standard deviation and quartiles of bird data were derived for different phases of the ENSO and IOD. Threshold SST anomalies were applied: $\pm 0.5^{\circ} \mathrm{C}$ to classify ENSO events following NOAA (2015); and $\pm 0.3^{\circ} \mathrm{C}$ to classify IOD events. These values divided the data approximately into thirds. Compositing like this is helpful when searching for gross climate signatures in noisy data or when small samples may be non-linearly related to conditioning variable(s) (in this case ENSO and/or IOD). The non-parametric Kolmogorov-Smirnov (KS) and Mann-Whitney U tests were used to evaluate significance of differences in the distribution of monthly weather (precipitation and temperature) and mean bird counts (SR and marker species) respectively under contrasting ENSO/ IOD phases.

\section{Results}

Correlation of species richness and of marker species counts with climate variables Climate and bird statistics vary between TN and Goa. TN is much warmer and drier than Goa (Figure 2). However, both regions have highest SR during JanuaryFebruary and lowest in June-August (Figure 3); SR and counts of marker species are 
higher in Goa than TN (Figure 4). Consecutive monthly SR are strongly (lag-1) autocorrelated in both states (Table 1) so effective sample sizes are reduced. This means that there is a higher than stated chance of making a Type I error for each correlation result. Moreover, because of the number of statistical tests $(\sim 300)$ about 15 'significant' results would be expected to occur by chance at the $5 \%$ confidence level. With these issues in mind, three points are highlighted. First, no significant correlations were detected between concurrent monthly SR and any climate variable. Second, the majority of lagged correlations in Table 1 are positive - higher SR and counts of marker species generally follow warmer/wetter conditions. The one exception is SR in winter which tends to be lower in Goa when the preceding SWM is wet. Third, bird communities appear to be more sensitive to climate variations in Goa than in TN.

Composite analysis of ENSO and IOD effects on weather and bird communities Compositing by ENSO and/or IOD phase leads to more fragmented series and hence reduces autocorrelation in pooled data. Contrary to expectations (Dai and Wigley, 2000), monthly precipitation totals were on average higher under El Niño than La Niña during the study period (Figure 5). Precipitation totals were also unexpectedly higher under negative rather than positive IOD. As anticipated, there was considerable variability in monthly precipitation within phases in both states. There was a significant $(p=0.04)$ difference in mean precipitation between IOD phases, and weak ( $p=0.09$ ) difference between ENSO phases in Goa (Table 2 and Figure 5).

However, the KS statistic reveals that there are significant differences in the distribution of monthly precipitation totals between contrasting ENSO $(p=0.05)$ and 
IOD $(p=0.02)$ phases in Goa, and weak differences under the IOD $(p=0.08)$ in TN. Air temperatures were greater under El Niño than La Niña (and under positive IOD compared with negative IOD) (Figure 6). According to the KS statistic, there are significant differences in the distribution of monthly mean temperature anomalies under contrasting ENSO $(p=0.05)$ and IOD $(p=0.05)$ phases in Goa, and under ENSO $(p=0.01)$ in TN.

SR and marker species counts also vary by ENSO and IOD phase in both states (Figure 7). In TN, counts of Kites were statistically different depending on phase of IOD; in Goa counts of all three marker species vary significantly with ENSO phase (Table 2). In TN, neutral-IOD years had the highest concurrent number of Kites. In Goa, El Niño years had the highest average number of Kites and Herons (with most abundant Ducks under neutral ENSO phases). La Niña phases had significantly lower numbers of marker birds (Figure 7).

Further analysis of the combined influence of climate modes on SR for TN reveals that positive IOD- neutral ENSO are associated with the lowest mean SR (18) and neutral IOD- El Niño with the highest SR (110). In Goa, the lowest (49) and highest (131) mean SR occurred under concurrent negative IOD-La Niña and negative IODEl Niño events respectively (Table 3).

Due to small sample sizes, care must be taken when interpreting results for individual species, especially those with relatively low abundance. With this in mind, the highest median counts for marker species occurred under neutral IOD-El Niño events for Kites (19), Herons (15) and Ducks (159) in Goa, and for Kites (12) and Herons (126) 
in TN. Positive IOD-La Niña phases had the lowest counts for the same species. In TN, Ducks were most abundant (19) during neutral IOD-neutral ENSO years.

\section{Discussion}

This study searched for potential ENSO and IOD signatures in the weather statistics and bird communities of two states of India using correlation and composite analyses. Due to autocorrelated series, small sample sizes and number of statistical tests, there is greater likelihood of Type I errors when interpreting unadjusted correlation results. Overall, however, higher SR and marker bird counts were associated with warmer/wetter conditions (Table 1 ). In TN, this may partly reflect autumn migration which begins in June bringing large numbers of migratory birds south to TN (Sullivan et al. 2011). Species such as the Indian Robin nest in June to September as this strategy improves sourcing of nest-building material and seeds for both adults and nestlings (Middleton 1979). House Sparrows have multiple broods per year and finish their nesting activities as late as September (Vickery et al. 1992).

In Goa, conditions are generally more favourable for birds during wet winter and premonsoon seasons. This may encourage arrival of long-distant and altitudinal migrants such as the Greenish Warbler at wintering sites (Grewal et al. 2002). Raptors and water birds breed during this season due to increased prey and water availability following the monsoon (Grewal et al. 2002). A wetter pre-monsoon season increases food and water availability as well as reduces negative impacts of high temperatures on eggs and young birds (Grewal et al. 2002). 
Lagged associations between weather and SR were generally stronger than concurrent correlations in both TN and Goa (Table 1). This is unsurprising as SR reflects the indirect impacts of climate on species-dependent food availability, prey, competition, habitats and migration (Catry et al. 2013; Favero and Becker 2006; Feldstein 2003; Holmgrem et al. 2001; Jaksic and Farina 2010; Monticelli et al. 2008; Zduniak et al. 2010). The lag-interval of strongest correlation varies by bird species, climate index, season, and region.

Compositing bird counts by ENSO and IOD phase reduces the influence of outliers on correlation statistics whilst integrating the direct/indirect effects of prevailing and antecedent weather. Contrasting ENSO and IOD phases also have different distributions of monthly precipitation and temperature, most notably in Goa. This is an appealing technique for detecting climate signals in bird data given the small samples and uncertain quality of bird records; the opposing view is that compositing amalgamates diverse, species-dependent responses to the same climate stressor(s). Hence, it is informative to consider the behaviour and life-cycle traits of individual species. Nonetheless, there may be counteracting effects on habitat, resource availability, security of nesting sites, avoidance of predators, and so forth.

In Goa, Kite, Heron and Duck counts were higher during El Niño than La Niña events. In TN, SR and counts of Kites are highest during neutral and negative IOD phases (Figure 8). This suggests that birds in the respective regions on balance thrive better under concurrent wetter/warmer weather. Even so, drier conditions are sometimes favourable since the Kite feeds on dead fish, crabs and carrion (Grewal et al. 2002). Indian Pond Herons also benefit during dry periods when wetlands shrink 
and there are higher concentrations of prey (Gadgil and Ali 1975). Conversely, heavy precipitation and flooding may destroy nesting and breeding grounds (Poiani 2006).

Wetter conditions also indirectly benefit birds through vegetation and resource availability or directly by triggering breeding and improved clutch size (Lloyd 2008). ENSO driven precipitation anomalies contribute to vegetation pulses or die-back with consequences for habitat, seed/ nectar availability, shrub, and perennial cover for prey (Holmgrem et al. 2001). For predators such as the Kite, there may be delayed responses to plant-mediated ENSO impacts that are not fully detected by concurrent or lagged correlations even over 12 months. Local migrants such (as the marker species) have stronger, regional associations with ENSO than long-distant migrants as the latter respond to annual temperature cues and are less affected by variations in weather unless it is a very strong ENSO as in 2015.

IOD and ENSO phases are known to operate in concert to dampen regional weather anomalies (Ashok et al. 2004) and thereby impact bird communities. Relatively low SR occurred during combined positive IOD-neutral ENSO phases in both TN and Goa (Table 3). This combination favoured drier conditions during the study period. Conversely, SR was highest under neutral IOD-EI Niño phases in TN, and under negative IOD-EI Niño phases in Goa. These conditions favoured higher rainfall during the study period. All three marker species in Goa and the Kites and Heron in TN recorded highest median counts during coincident neutral IOD-EI Niño phases.

Our pilot study shows that it is far from straightforward to discern climate signatures in bird data due to small samples, highly autocorrelated series, uncertainty about the 
quality of observations, compensating direct and indirect effects mediated by habitats, life-cycle traits and resource availability. Over decadal time-scales, detection may be confounded by other indirect or non-climatic stressors due to land use and cover change, habitat loss, extinction of co-dependent species, pollution, urban heat islands or human activity (Burger 1981). Nonetheless, our composite analysis has revealed variations in SR and counts of marker species that are contingent upon modes of climate variability in India. The approach is inherently multivariate since the modes are associated with different distributions of temperature and precipitation.

\section{Conclusions}

Previous research shows that ENSO and IOD affect the climate of India. Here we confirm that both modes of climate variability have a discernible influence on the distribution of monthly precipitation and temperature, most notably in Goa. However, little is known about how these modes of climate variability, with attendant weather anomalies, translate into meaningful changes in bird communities. We find that there is generally higher SR under wetter/warmer weather conditions - but formal detection of any covariance is hampered by autocorrelation and small sample sizes.

Overall, counts of selected marker species (in Goa) were significantly higher under El Niño phases (which were wetter/warmer than average during the study period). These findings are relevant because anthropogenic climate change could impact ENSO, the intensity of the Asian monsoon and hence SR over coming decades (Gergis and Fowler 2008). In both states, SR was relatively high under concurrent neutral IOD-El Niño phases. It is assumed that marker species benefit under these 
wetter conditions from increased habitat area and more successful breeding (Grewal et al. 2002; Gadgil and Ali 1975).

The compositing technique used in this pilot study could be applied to other parts of South Asia, to test the generality of our findings. The weak or undetectable impact of precipitation and temperature on bird communities at a monthly timescale; broader regional variations in the influence of IOD on bird communities beyond the two states investigated; and the combined effect of ENSO and IOD on birds all warrant further investigation. Moreover, compositing could be applied to other taxa to determine whether bird communities are the most sensitive 'canary in the mine' for detecting climate-driven changes in the fauna and flora of India.

\section{Acknowledgements}

Thanks to IITM and IMD Pune for providing precipitation data, eBirds.com for bird data, and Dr Radha Gopalan for logistical support. 


\section{References}

Ashok K, Guan Z and Yamagata T 2001 Impact of the Indian Ocean Dipole on the relationship between the Indian monsoon rainfall and ENSO Geophysical Research Letters 28 4499-4502

Ashok K, Guan Z, Saji N H and Yamagata T 2004 Individual and combined influences of ENSO and the Indian Ocean Dipole on the Indian Summer Monsoon Journal of Climate 17 3141-3155

Burger $\mathbf{J} 1981$ The effect of human activity on birds at a coastal bay Biological Conservation 21 231-241

Catry T, Ramos J A, Catry I, Monticelli D and Granaderio J P 2013 Inter-annual variability in the breeding performance of six tropical seabird species: influence of life-history traits and relationship with oceanographic parameters Marine Biology $1601189-1201$

Caviedes C N 2001 El Niño in history: storming through the ages University Press of Florida, Gainesville

DahImann L 2009 Climate Variability: Oceanic Niño Index (https://www.climate.gov/news-features/understanding-climate/climate-variabilityoceanic-ni\%C3\%B10-index) Accessed 25 February 2016

Dai A and Wigley T M L 2000 Global patterns of ENSO-induced precipitation Geophysical Research Letters 27 1283-1286

eBird 2015 eBird Basic Dataset (http://ebird.org/ebird/data/download) Accessed 25 May 2015

Favero M and Becker P H 2006 Effect of North Atlantic Oscillation and El NiñoSouthern Oscillation on return rates, body mass and timing of migration of Common Terns Sterna hirundo breeding in Germany in Boere G C Galbraith C A 
and Stroud D A eds Waterbirds around the world The Stationery Office, Edinburgh 405-409.

Feldstein S B 2003 El Niño/Southern oscillation and North American land birds Birding 606-614

Foden W B, Butchart S H M, Stuart S N, Vie J C, Akcakaya R, Angulo A, DeVantier L M, Gutsche A, Turak E, Cao L, Donner S D, Katariya V, Bernard R, Holland R A, Hughes A F, O'Hanlon S E, Garrnett S T, Sekercioglu C H and Mace G M 2013 Identifying the world's most climate change vulnerable species: A systematic trait-based assessment of all birds, amphibians and corals PLOS ONE 8 e65427

Gadgil M and Ali S 1975 Communal roosting habits of Indian birds Journal of the Bombay Natural History Society 72 716-72

Gergis J L and Fowler A M 2008 A history of ENSO events since A.D. 1525: Implications for future climate change Climatic Change 92 343-387

Grewal B, Harvey B and Pfister O 2002 A photographic guide to the birds of India Periplus Edition, Singapore

Holmgrem M, Scheffer M, Ezcurra E, Gutierrez J R and Mohren G M J 2001 El Niño effects on the dynamics of terrestrial ecosystems Trends in Ecology \& Evolution 16 89-94

IITM 2015 Data Archival (http://www.tropmet.res.in/Data\%20Archival-51-Page) Accessed 25 May 2015

IMD 2016 Monsoon (http://www.imd.gov.in/pages/monsoon main.php) Accessed 20 February 2016 
Jaksic F M and Farina J M 2010 El Niño and the birds: A resource-based interpretation of climatic forcing in the Southeastern Pacific Anales Instituto de la Patagonia 38 121-140

Krishnamurthy V and Goswami B N 2000 Indian Monsoon-ENSO relationship on interdecadal timescale Journal of Climate 13 579-595

Lloyd P 2008 Rainfall as a breeding stimulus and clutch size determinant in South African arid-zone birds Ibis $141637-643$

Middleton A L A 1979 Influence of Age and Habitat on on Reproduction by the American Goldfinch Ecology 60 418-432

Monticelli D, Ramos J A, Guerreiro-Milheiras S A and Doucet J L 2008 Adult Survival of Tropical Roseate Terns Breeding on Aride Island, Seychelles, Western Indian Ocean Waterbirds 31 330-337

NOAA 2015 ONI Data (http://www.esrl.noaa.gov/psd/data/correlation/oni.data) Accessed 2 July 2015

NOAA 2016 IOD Data

(https://iridl.Ideo.columbia.edu/SOURCES/.NOAA/.NCDC/.ERSST/.version4/.IOD/. C1983-2015/.iod/T+exch+table-+text+text+skipanyNaN+-table+.html) Accessed 12 July 2016

Osborn T J and Jones P D 2014 The CRUTEM4 land-surface air temperature data set: construction, previous versions and dissemination via Google Earth Earth System Science Data 6 61-68

Pearce-Higgins J W, Eglington S M, Martay B and Chamberlain D E 2015 Drivers of climate change impacts on bird communities Journal of Animal Ecology 84 943954 
Poiani A 2006 Effects of Floods on Distribution and Reproduction of Aquatic Birds Advances in Ecological Research 39 63-83

Saji N H, Goswami B N, Vinayachandran P N and Yamagata T 1999 A dipole mode in the tropical Indian Ocean Nature 401 360-363

Sullivan B, Iliff M, Farnsworth A and Wood C 2011 Understanding birds and weather: Fall birding basics eBird (http://ebird.org/content/ebird/news/fall-birding$\underline{\text { basics/) }}$

Vickery P D, Hunter Jr M L and Wells J V 1992 Evidence of incidental nest predation and its effects on nests of threatened grassland birds Oikos 281-288

Zduniak P, Yosei R, Sparks T H, Smit H and Tryjanowski P 2010 Rapid advances in the timing of the spring passage migration through Israel of the steppe eagle Aquila nipalensis Climate Research 42 217-222 
Table 1 Spearman rank correlations [in brackets] between bird and climate data. SR is species richness, $\mathrm{T}$ is temperature, $\mathrm{P}$ is precipitation, $\mathrm{ONI}$ is Oceanic Niño Index, SWM is south west monsoon, PM is pre-monsoon, DJF is winter, JJA is summer. The Bonferroni thresholds for significant associations are $p \leq 0.0012$ for $\mathrm{SR}$, and $p \leq 0.0038$ for marker species. Only the strongest lag correlation is reported for each family of tests.

\begin{tabular}{|c|c|}
\hline Tamil Nadu & Goa \\
\hline $\begin{array}{l}\text { Species richness (all months) } \\
\text { SR lag } 1[r=0.76, p<0.0001] \\
\text { T lag } 1[r=0.18, p=0.0397] \\
\text { Species richness (SWM) } \\
\text { T SWM } r=0.33, p=0.0461] \\
\text { Species richness (JJA) } \\
\text { T JJA lag } 7[r=0.52, p=0.0225] \\
\text { Species richness }(D J F) \\
\text { P DJF lag } 2[r=0.51, p=0.0182]\end{array}$ & $\begin{array}{l}\text { Species richness (all months) } \\
\text { SR lag } 1[r=0.58, p<0.0001] \\
\text { P lag } 5[r=0.39, p<0.0001] \\
\text { T lag } 5[r=-0.21, p=0.0169] \\
\text { ONI lag } 4[r=0.22, p=0.0122] \\
\text { Species richness (DJF) } \\
\text { P DJF }[r=0.38, p=0.0461] \\
\text { P DJF lag } 4[r=-0.51, p=0.0312] \\
\text { Species richness }(P M) \\
\text { P PM }[r=0.34, p=0.0500]\end{array}$ \\
\hline $\begin{array}{l}\text { Kite numbers (all months) } \\
\begin{array}{l}\mathrm{P} \text { lag } 5[r=0.33, p=0.0402] \\
\mathrm{T} \text { lag } 1[r=0.41, p=0.0095] \\
\text { ONI }[r=0.35, p=0.0139]\end{array}\end{array}$ & $\begin{array}{l}\text { Kite numbers (all months) } \\
\qquad \begin{array}{l}\mathrm{P}[r=0.23, p=0.0156] \\
\mathrm{P} \text { lag } 5[r=0.35, p=0.0002] \\
\mathrm{T}[r=0.23, p=0.0156] \\
\text { ONI }[r=0.41, p<0.0001] \\
\text { ONI lag } 5[r=0.44, p<0.0001]\end{array}\end{array}$ \\
\hline $\begin{array}{l}\text { Heron numbers (all months) } \\
\qquad \mathrm{T}[r=0.30, p=0.0453]\end{array}$ & $\begin{array}{l}\text { Heron numbers (all months) } \\
\qquad \begin{array}{l}\mathrm{P}[r=0.35, p=0.0003] \\
\mathrm{P} \text { lag } 5[r=0.39, p<0.0001] \\
\mathrm{T}[r=0.31, p=0.0014] \\
\mathrm{T} \text { lag } 5[r=0.21, p=0.0323] \\
\text { ONI }[r=0.41, p<0.0001] \\
\text { ONI lag } 5[r=0.44, p<0.0001]\end{array}\end{array}$ \\
\hline $\begin{array}{l}\text { Duck numbers (all months) } \\
\qquad \text { ONI lag } 10[r=0.51, p=0.0451]\end{array}$ & $\begin{array}{l}\text { Duck numbers (all months) } \\
\qquad \begin{array}{l}\mathrm{P} \text { lag } 5[r=0.32, p=0.0135] \\
\mathrm{T}[r=0.45, p=0.0003] \\
\text { ONI }[r=0.38, p=0.0030] \\
\text { ONI lag } 5[r=0.47, p=0.0002]\end{array}\end{array}$ \\
\hline
\end{tabular}


Table 2 Mann-Whitney $U$ (with significance) of differences between SR and marker species counts under El Niño versus La Niña or positive versus negative IOD events.

\begin{tabular}{|l|c|c|}
\hline Region & EI Niño-La Niña & Positive-Negative IOD \\
\hline Tamil Nadu & & \\
Precipitation & $467(0.33)$ & $310(0.31)$ \\
Temperature & $392(0.11)$ & $235(0.27)$ \\
All species & $435(0.30)$ & $201(0.11)$ \\
Kite & $47(0.39)$ & $\mathbf{3 ( 0 . 0 1 )}$ \\
Heron & $49(0.29)$ & $8(0.29)$ \\
Duck & sample too small & sample too small \\
\hline Goa & & \\
Precipitation & $463(0.09)$ & $\mathbf{2 0 6}(\mathbf{0 . 0 4 )}$ \\
Temperature & $472(0.11)$ & $98(0.11)$ \\
All species & $491(0.15)$ & $108(0.23)$ \\
Kite & $\mathbf{2 9 4 ( 0 . 0 3 )}$ & $103(0.49)$ \\
Heron & $\mathbf{2 3 9 ( 0 . 0 1 )}$ & $84(0.28)$ \\
Duck & $\mathbf{6 6 ( 0 . 0 5 )}$ & $15(0.59)$ \\
\hline
\end{tabular}


Table 3 Mean and standard deviation of species richness under combined ONI and IOD phases for TN and Goa (with number of months of data in brackets).

\begin{tabular}{|c|c|c|c|c|}
\hline \multirow{2}{*}{\multicolumn{2}{|c|}{ Tamil Nadu species counts }} & \multicolumn{3}{|l|}{ ONI phase } \\
\hline & & \multirow{2}{*}{$\begin{array}{l}\text { La Niña } \\
39 \pm 8(6)\end{array}$} & \multirow{2}{*}{\begin{tabular}{|l|} 
Neutral \\
$18 \pm 13(5)$ \\
\end{tabular}} & \multirow{2}{*}{\begin{tabular}{|l|} 
El Niño \\
$42 \pm 34(12)$ \\
\end{tabular}} \\
\hline IOD phase & Positive & & & \\
\hline & Neutral & $53 \pm 60(16)$ & $57 \pm 61(45)$ & $110 \pm 108(23)$ \\
\hline & Negative & $40 \pm 24(6)$ & $61 \pm 52(15)$ & $63 \pm 42(3)$ \\
\hline \multirow{2}{*}{\multicolumn{2}{|c|}{ Goa species counts }} & \multicolumn{3}{|l|}{ ONI phase } \\
\hline & & La Niña & Neutral & El Niño \\
\hline \multirow[t]{3}{*}{ IOD phase } & Positive & $64 \pm 57(5)$ & $55 \pm 62(4)$ & $72 \pm 27(7)$ \\
\hline & Neutral & $77 \pm 46(27)$ & $95 \pm 64(44)$ & $120 \pm 113(24)$ \\
\hline & Negative & $49 \pm 27(6)$ & $107 \pm 77(10)$ & $131 \pm 79(2)$ \\
\hline
\end{tabular}




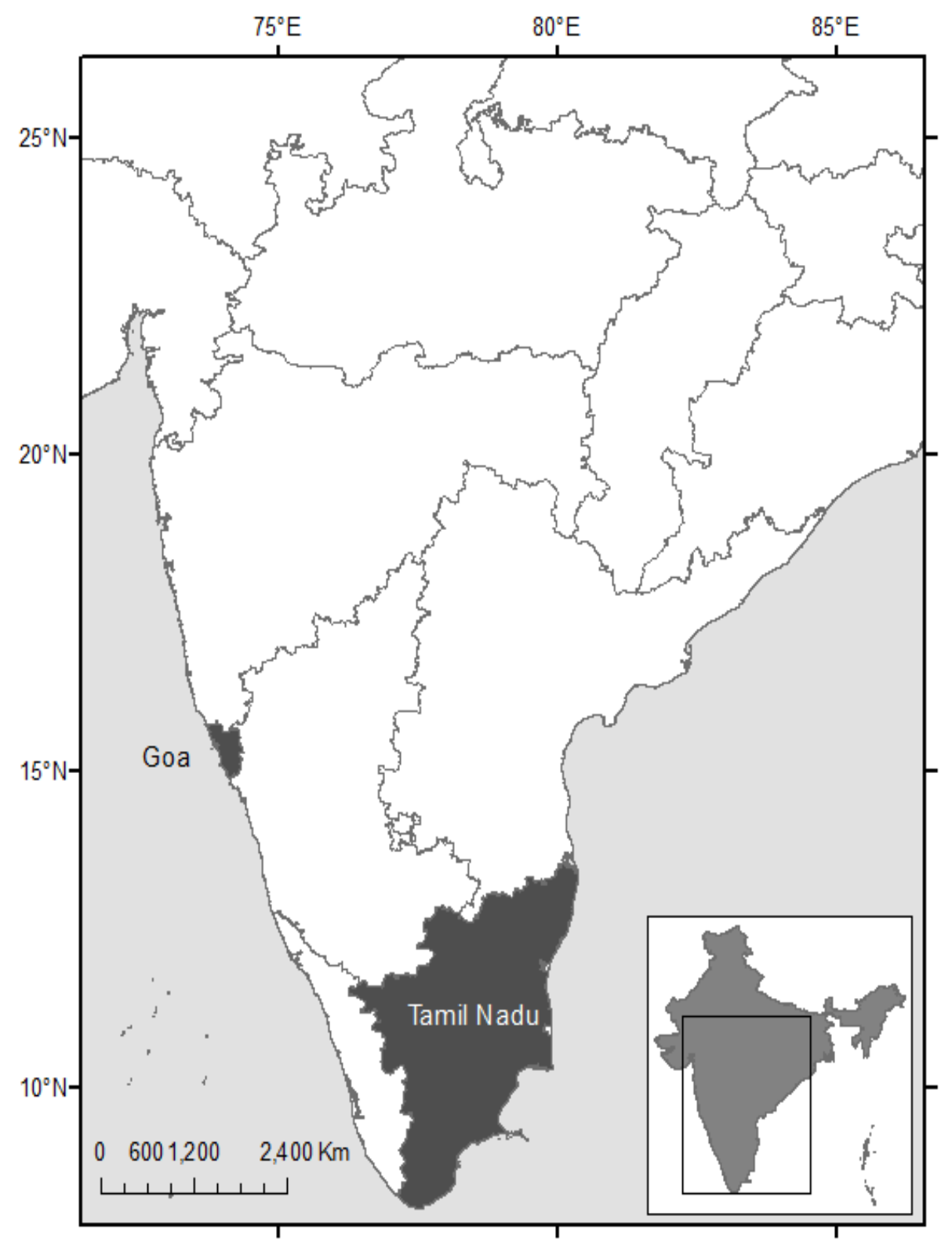

Figure 1 Location of study areas. 

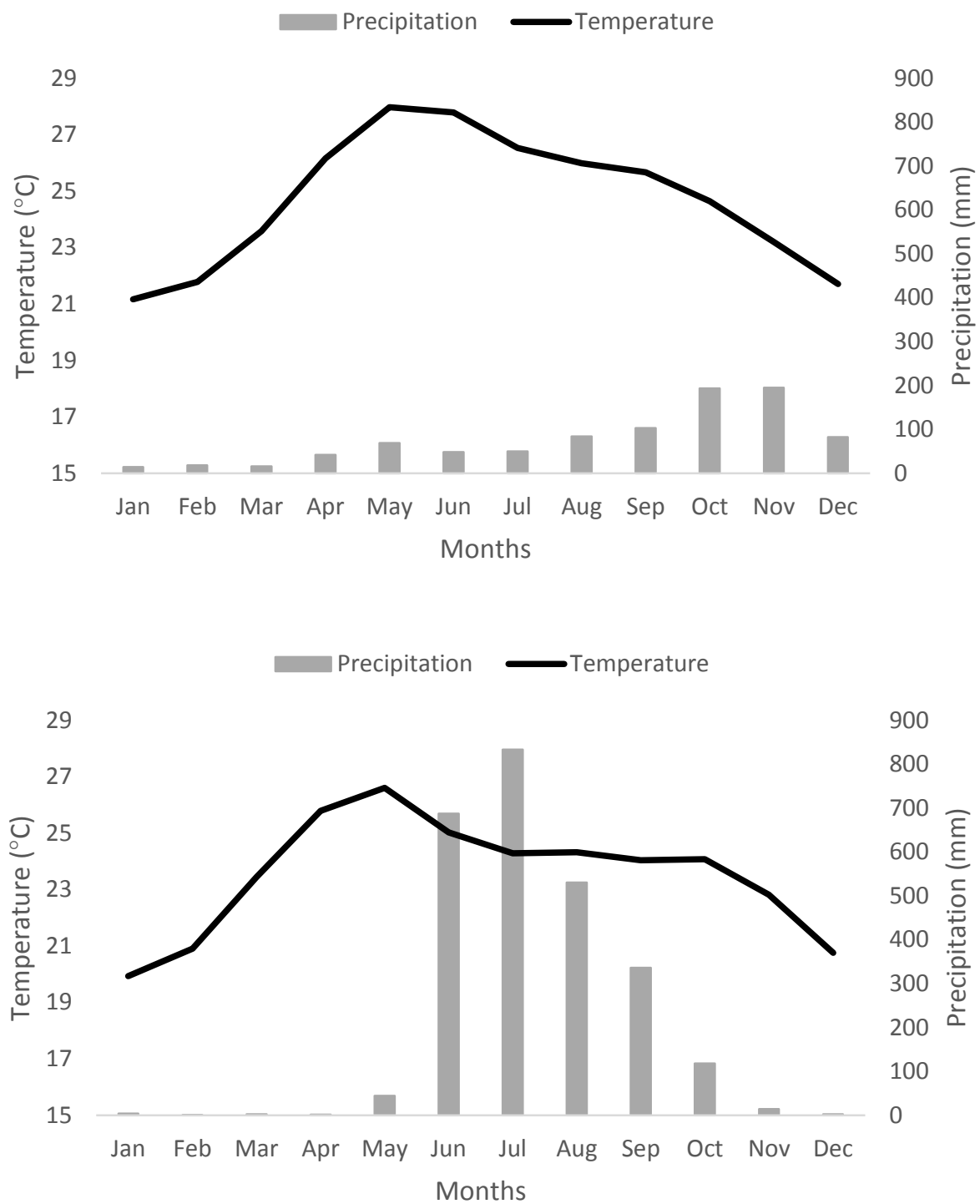

Figure 2 Monthly mean temperature and precipitation totals in Tamil Nadu (upper panel) and Goa (lower panel) 1990-2014. 


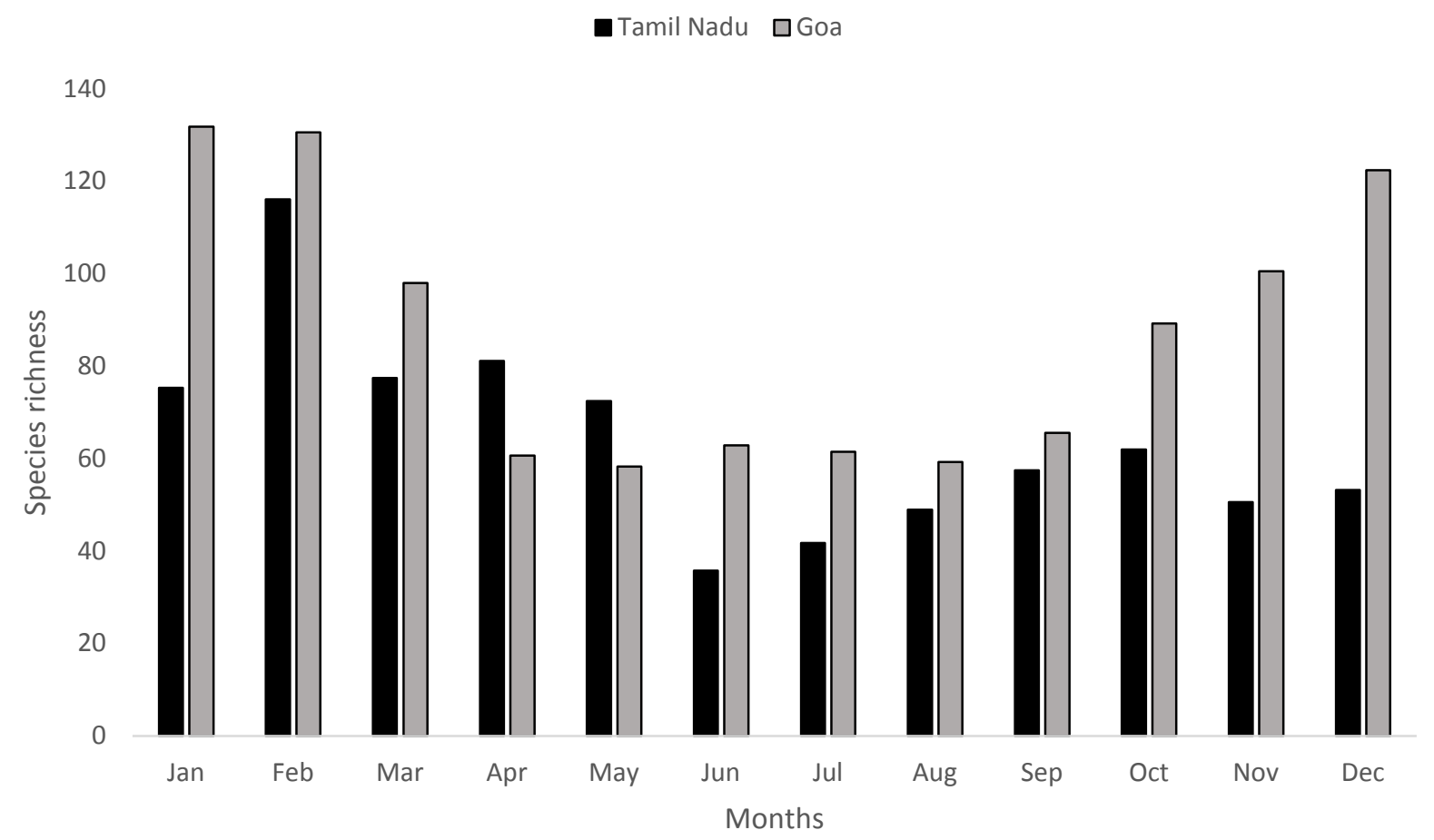

Figure 3 Mean species richness by month in Tamil Nadu and Goa 1990-2015. 

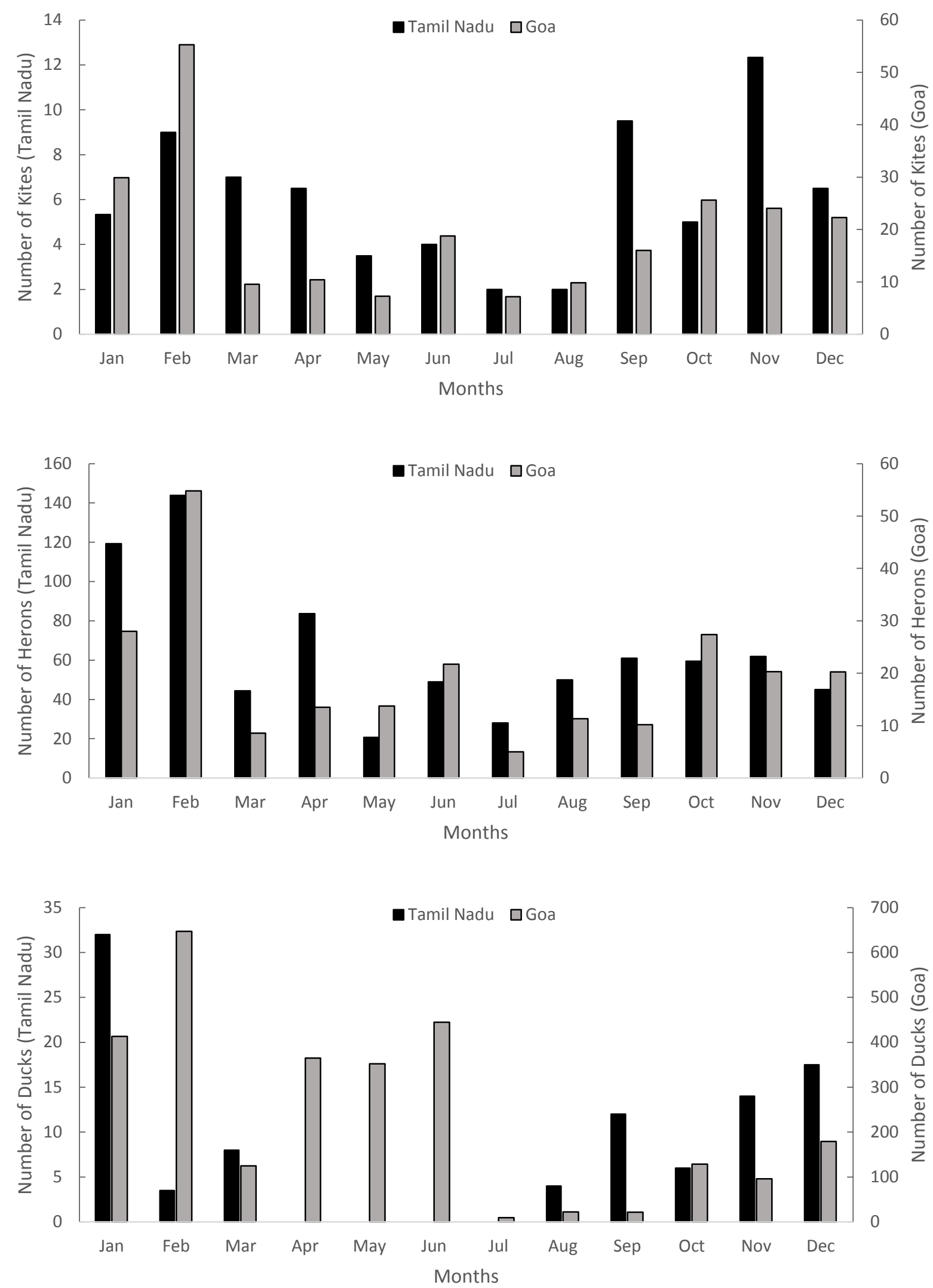

Figure 4 Mean number of Kites (upper panel), Herons (centre panel), and Ducks (lower panel) per month in Tamil Nadu and Goa 1990-2015. 

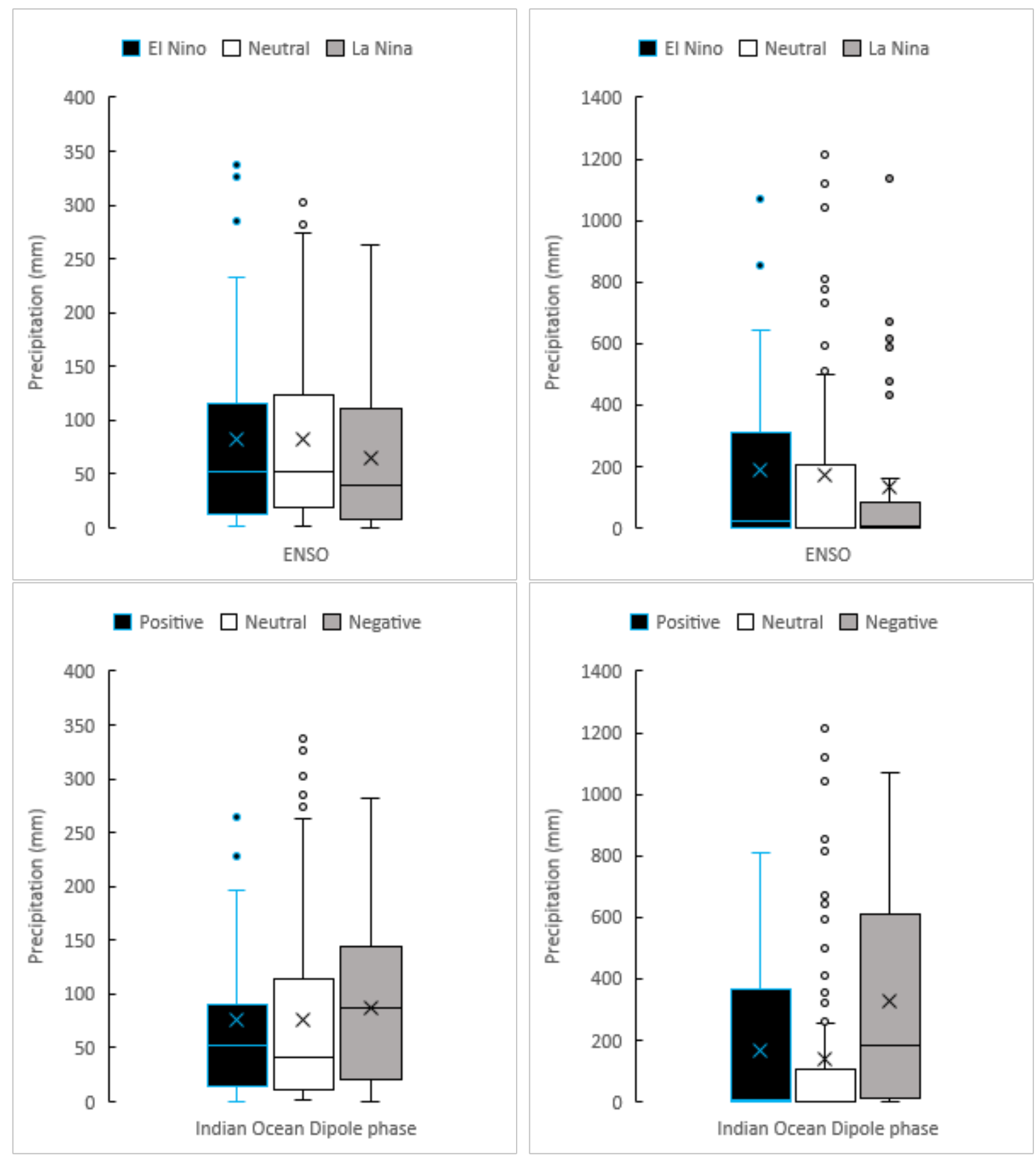

Figure 5 Precipitation ( $\mathrm{mm}$ ) by ENSO (upper panel) and IOD (lower panel) phase in Tamil Nadu (left) and Goa (right). Black bars: El Niño/Positive IOD; White: Neutral ENSO/Neutral IOD; Grey bars: La Niña/Negative IOD. Crosses are the mean; lines the median; boxes the interquartile range (IQR); T-bars are $1.5 \times$ IQR; points are outliers. 

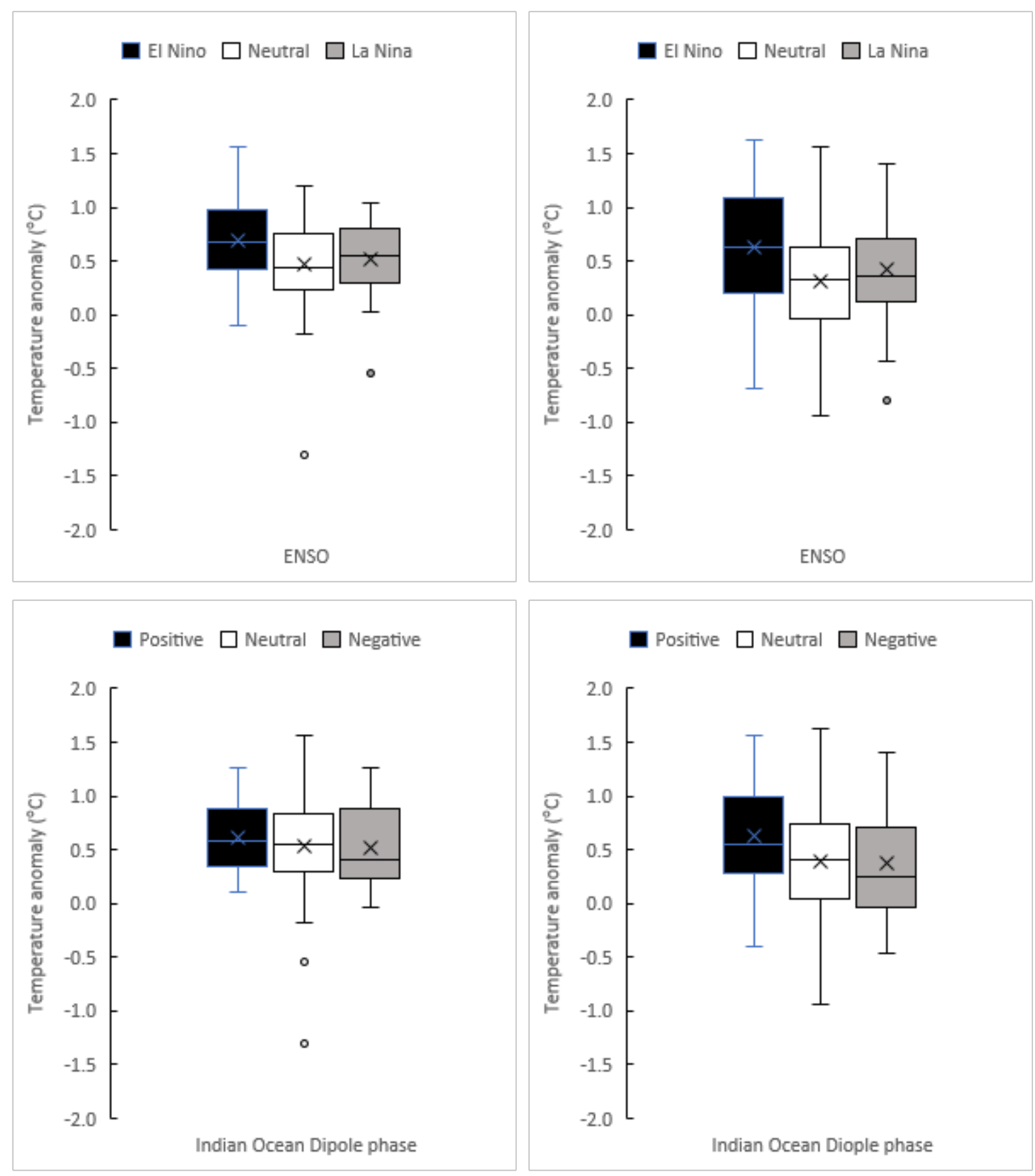

Figure 6 As in Fig. 5 but for temperature. 

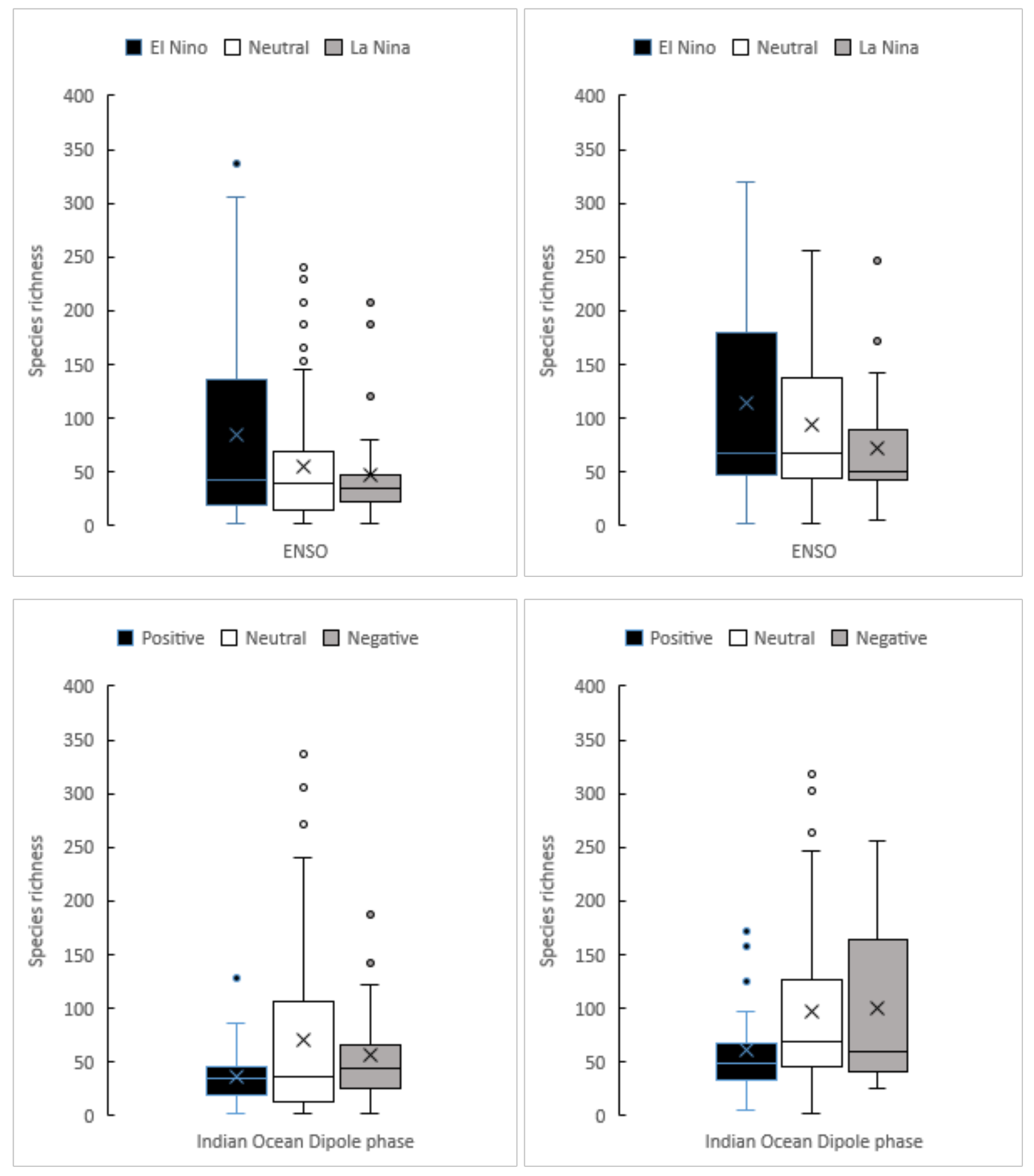

Figure 7 As in Fig.5 but for species richness. 

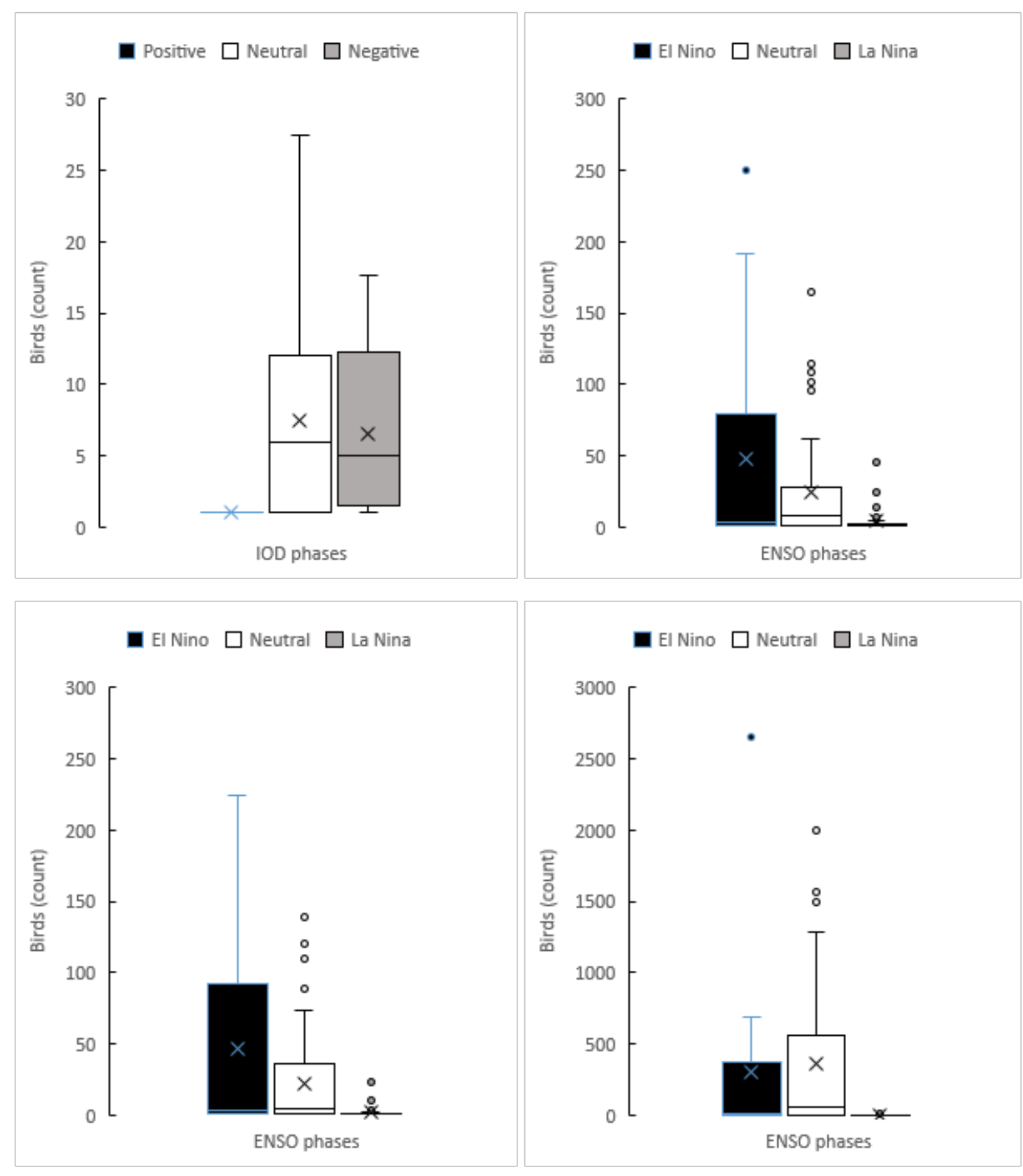

Figure 8 Marker bird counts during ENSO and IOD phases. Top left: Kites in TN (IOD). Top right: Kites in Goa (ENSO). Lower left: Herons in Goa (ENSO). Lower right: Ducks in Goa (ENSO). Black bars: El Niño/ positive IOD phase; White bars: neutral ENSO/ neutral IOD phase; Grey bars: La Niña/ negative IOD phase. 